\title{
Article
}

\section{X-Ray Photoelectron Spectroscopy Depth Profiling of As-Grown and Annealed Titanium Nitride Thin Films}

\author{
Monzer Maarouf ${ }^{1}$, Muhammad Baseer Haider ${ }^{1, * \mathbb{D}}$, Qasem Ahmed Drmosh ${ }^{2} \mathbb{D}$ and Mogtaba B. Mekki ${ }^{1}$ \\ 1 Department of Physics, King Fahd University of Petroleum and Minerals, Dhahran 31261, Saudi Arabia; \\ monther.marouf@gmail.com (M.M.); mogtaba@kfupm.edu.sa (M.B.M.) \\ 2 Center of Excellence for Nanotechnology, King Fahd University of Petroleum and Minerals, \\ Dhahran 31261, Saudi Arabia; drmosh@kfupm.edu.sa \\ * Correspondence: mhaider@kfupm.edu.sa; Tel.: +966-13-860-2371
}

check for updates

Citation: Maarouf, M.; Haider, M.B.; Drmosh, Q.A.; Mekki, M.B. X-Ray Photoelectron Spectroscopy Depth Profiling of As-Grown and Annealed Titanium Nitride Thin Films. Crystals 2021, 11, 239. https://doi.org/ $10.3390 /$ cryst11030239

Academic Editor: Kavian Cooke

Received: 9 February 2021

Accepted: 24 February 2021

Published: 27 February 2021

Publisher's Note: MDPI stays neutral with regard to jurisdictional claims in published maps and institutional affiliations.

Copyright: (c) 2021 by the authors. Licensee MDPI, Basel, Switzerland. This article is an open access article distributed under the terms and conditions of the Creative Commons Attribution (CC BY) license (https:// creativecommons.org/licenses/by/ $4.0 /)$.

\begin{abstract}
Titanium nitride thin films were grown on $\mathrm{Si}(001)$ and fused silica substrates by radio frequency reactive magnetron sputtering. Post-growth annealing of the films was performed at different temperatures from $300{ }^{\circ} \mathrm{C}$ to $700{ }^{\circ} \mathrm{C}$ in nitrogen ambient. Films annealed at temperatures above $300^{\circ} \mathrm{C}$ exhibit higher surface roughness, smaller grain size and better crystallinity compared to the as-grown film. Bandgap of the films decreased with the increase in the annealing temperature. Hall effect measurements revealed that all the films exhibit n-type conductivity and had high carrier concentration, which also increased slightly with the increase in the annealing temperature. A detailed depth profile study of the chemical composition of the film was performed by x-ray photoelectron spectroscopy confirming the formation of Ti-N bond and revealing the presence of chemisorbed oxygen in the films. Annealing in nitrogen ambient results in increased nitrogen vacancies and non-stoichiometric TiN films.
\end{abstract}

Keywords: thin film semiconductors; titanium nitride; magnetron sputtering; $X$-ray photoelectron spectroscopy; atomic force microscopy

\section{Introduction}

Titanium nitride (TiN) is a wide bandgap semiconductor with a wide range of interesting electrical and mechanical properties. Despite its wide bandgap, TiN has a high carrier concentration and hence TiN thin films can be used as a metal gate in microelectronic devices and can potentially be used as cathodes in electrochemical capacitors [1-4]. TiN is extremely hard-mechanical material and is often coated on drilling bits for its hardness and anticorrosive properties [5-7]. Moreover, TiN is not a toxic material and can be used in medical devices as well [8,9]. TiN exhibits both covalent and metallic bonds. Covalent bonds occur in the hybridized $\mathrm{p}$ and d orbitals, whereas metallic bonds occur in d orbitals. Due to the mixture of such bonding, TiN exhibits both metallic and semiconducting properties. For example, high electrical conductivity of TiN is due to the metallic bonding whereas hardness, high melting point and excellent chemical stability are due to its covalent bonding nature $[10,11]$. There are several reports on the growth of titanium nitride thin films by chemical vapor deposition (CVD) [12,13], pulsed laser deposition (PLD) [14-16], radio frequency (RF) and DC magnetron sputtering [17-21], molecular beam epitaxy (MBE) [22,23], ion beam assisted deposition [24] and atomic layer deposition [25]. TiN is reported to have n-type conductivity and a direct bandgap ranging from $2.7 \mathrm{eV}$ to $4.06 \mathrm{eV}$. Bandgap variation in different reports is due to the difference in the growth conditions such as growth temperature, post growth treatment and $\mathrm{N}_{2} / \mathrm{Ar}$ flux ratio $[12,17,18,26]$.

Here, we report the influence of post-growth annealing temperature in nitrogen ambient on the structural, optical, electronic and chemical properties of titanium nitride thin films prepared by radio frequency (RF) magnetron sputtering. We report a detailed $X$-ray photoelectron spectroscopy (XPS) analysis and depth profiling of the as-grown and 
annealed TiN thin films to understand the cause of variations in the reported bandgap values. Such a detailed depth profile study has been lacking in the reported work on TiN thin films.

\section{Experimental Details}

Titanium nitride thin films were prepared on fused silica and single crystal silicon (001) substrates simultaneously by RF magnetron sputtering (Oerlikon Univex 350, Leybold, Germany) of titanium target in the presence of flowing argon (Ar) and nitrogen $\left(\mathrm{N}_{2}\right)$ gases. Fused silica substrates were used for the optical transmittance measurements and the films grown on $\mathrm{Si}(001)$ were used for all the other characterization reported here.

Substrates were first chemically cleaned by sonicating them first in acetone and then in isopropanol before placing them in the sputtering chamber. The chamber was evacuated to an initial pressure of about $\sim 1.5 \times 10^{-5}$ torr by pumping for several hours. During the deposition, substrates were kept at room temperature and were continuously rotated at six revolutions per minute for uniform thin film growth. Argon (99.999\% pure) and $\mathrm{N}_{2}$ (99.99\% pure) were used as sputtering gas and reactive gas respectively. Flow rate of $\mathrm{Ar}$ and $\mathrm{N}_{2}$ during the growth were fixed at 60 and 10 standard cubic centimeters per minute (sccm), respectively. Titanium (99.99\% pure) target was sputtered by setting the RF power to 100 Watt. During the growth, chamber pressure was maintained at $5.4 \times 10^{-3}$ torr and the deposition time was about one hour. After the growth, films were taken out of the chamber and placed in a furnace for annealing in the presence of nitrogen ambient at a $\mathrm{N}_{2}$ flow rate of $100 \mathrm{sccm}$. One film was not annealed and the other three films were annealed at a temperature of 300,500 , and $700{ }^{\circ} \mathrm{C}$ respectively. During the annealing, temperature was ramped at a rate of $5{ }^{\circ} \mathrm{C} / \mathrm{min}$ and after reaching the desired temperature, samples were kept at that temperature for three hours and then the furnace heater was turned off. The samples were kept inside the furnace under nitrogen ambient until the samples reached room temperature.

Surface morphology of the films was studied by atomic force microscopy (AFM) using non-contact mode ot tapping mode (Veeco Innova diSPM by Bruker, Billerica, MA, USA). AFM images were processed by applying three-point leveling to remove the unevenness in the appearance of the raw images that are due to small tilt in the substrate. Laplacian algorithm was used to mark the grains and the grain size was estimated by selecting the appropriate threshold that would result in a maximum number of grains in the grain statistics. Average threshold value for our samples was around 50\% $[27,28]$. Crystal structure of the films was studied using x-ray diffraction (Shimadzu XRD-6000 diffractometer, Kyoto, Japan equipped with $\mathrm{Cu}-\mathrm{K}_{\alpha}$ radiations of wavelength $1.548 \AA$ ). Normal incidence transmittance spectra of the samples were acquired in the range of 200 to $2000 \mathrm{~nm}$ by a UV-Visible Jasco V-570 spectrophotometer (Easton, MD 21601, USA). Hall effect measurements of the films were carried out using the four-probe Van der Pauw method [29]. Hall measurements were performed at room temperature using the ECOPIA HMS3000 system (Gyeonggi-do, Korea). Electrical contacts to the films were made using silver paint. Chemical composition of the films was determined by X-ray Photoelectron Spectroscopy (XPS), using a Thermo Fisher ESCALAB 250Xi spectrometer (Waltham, MA, USA) equipped with Al-K $\alpha$ source and the chamber pressure was about $4 \times 10^{-10}$ Torr. Depth profiling was performed by etching the surface of the films by bombarding them with argon ions of energy $3 \mathrm{KeV}$ for $30 \mathrm{~s}$. After each etching cycle, high-resolution XPS spectra for titanium (Ti2p), nitrogen (N1s) and oxygen (O1s) were acquired. Etching was performed until the film-substrate interface was reached.

\section{Results and Discussions}

Shown in Figure 1 are the XRD $\theta-2 \theta$ scans of the as-grown and the annealed samples. The XRD scan of S1 (as-grown) contains Si(001) peak along with $\mathrm{TiN}(220)$ and $\mathrm{TiN}(200)$ peaks. Highest intensity XRD peak of the film is of $\mathrm{TiN}(220)$, indicating the preferred growth direction for TiN film is along (220). XRD scan also contains a small peak of 
$\mathrm{TiO}_{2}(118)$ indicating the presence of oxygen in the film. Oxygen could be present in the chamber during the growth or it was chemisorbed on the surface when samples were exposed to air after the growth. It is quite unlikely for oxygen to be present during the growth because the chamber was evacuated for several hours prior to the growth to a pressure of $\sim 1.5 \times 10^{-5}$ torr. Moreover, highly pure argon and nitrogen gasses were used to ensure the high purity of the films. So most likely, oxygen was chemisorbed after the growth when the samples were exposed to air.

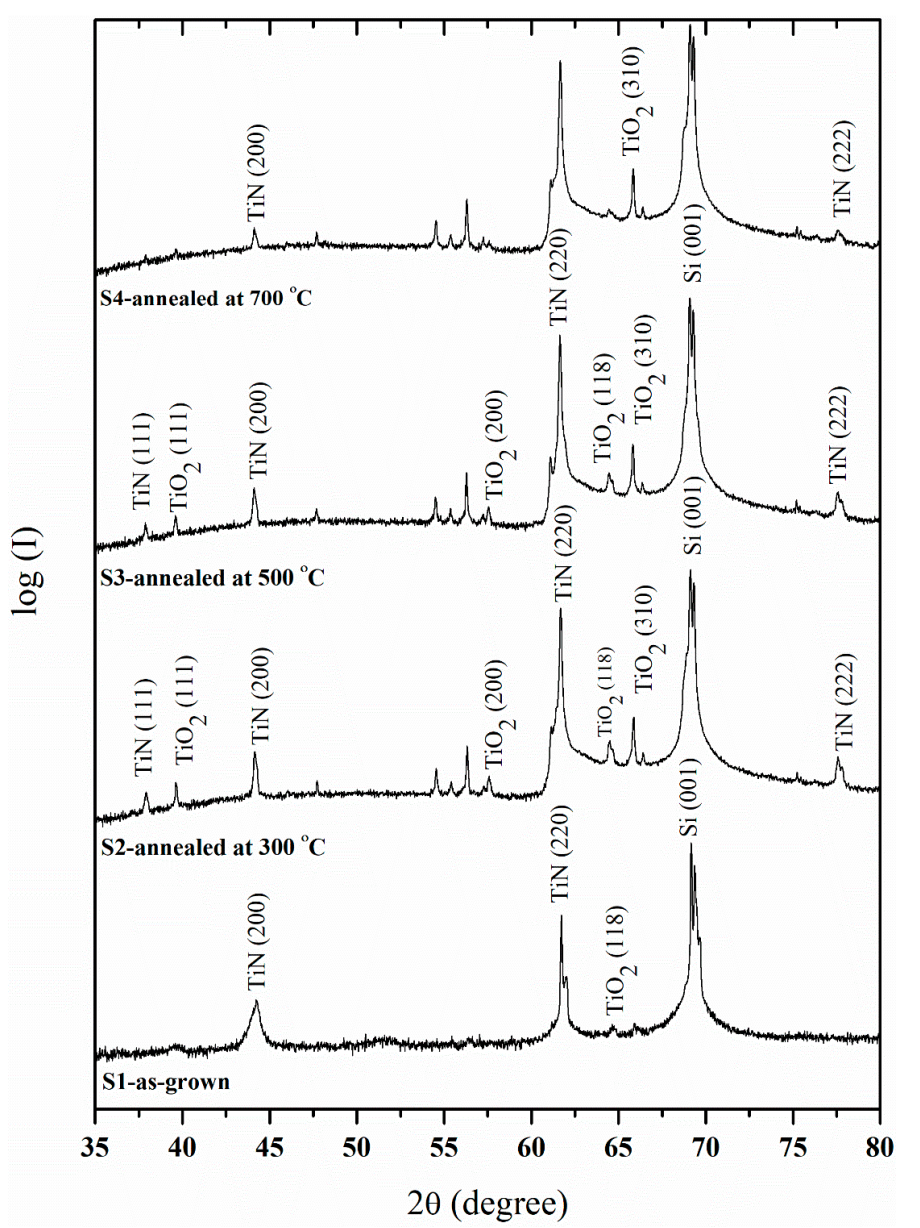

Figure 1. XRD scans of S1 (as-grown), S2 (annealed at $300{ }^{\circ} \mathrm{C}$ ), S3 (annealed at $500{ }^{\circ} \mathrm{C}$ ) and S4 (annealed at $700{ }^{\circ} \mathrm{C}$ ) TiN thin films.

XRD scans of the annealed samples (S2, S3 and S4) contain TiN (111) and TiN (222) peaks along with TiN (200) and TiN (220) with preferred orientation along $\mathrm{TiN}(220)$. There is also a noticeable increase in the number of $\mathrm{TiO}_{2}$ phases. XRD spectra reveal that the crystal structure of all TiN thin films is face centered cubic (FCC) [18]. The lattice constants of TiN films were calculated using Bragg's equation:

$$
n \lambda=2 d \sin \theta
$$

where $d=\frac{a}{\sqrt{h^{2}+k^{2}+l^{2}}}$.

The lattice constants were found to be $4.18,4.16,4.16$ and $4.17 \AA$ for S1, S2, S3 and S4, respectively, indicating a little effect of annealing on the lattice constant of the films. These values are considerably close to the reported values of TiN lattice constant of 4.20 and $4.22 \AA$ [30].

Full width at half maximum (FWHM) for TiN(200) peak decreases with the increase in the annealing temperature. It was found to be $0.50,0.23,0.22$ and 0.21 degrees for $\mathrm{S} 1, \mathrm{~S} 2$, S3 
and S4, respectively. A decrease in the FWHM of TiN(200) peak due to post growth annealing is an indication of increased crystallinity of the film along (200) direction. However, there was no significant change in the FWHM of TiN(222) and TiN(220) XRD peaks.

Surface morphology of the films was studied using atomic force microscopy. Twoand three-dimensional $5 \times 5 \mu^{2}$ AFM images of as-grown and annealed films on $\mathrm{Si}$ (001) substrate are shown in Figure $2 \mathrm{a}-\mathrm{h}$. Root mean square (RMS) roughness and the average grain size of the films as calculated from these images are given in Table 1. Surface morphology of the as-grown titanium nitride thin film is mostly smooth two-dimensional with few bright protrusions on the surface, which appear as column like structures in the $3 \mathrm{D}$ image. For sample S2, these protrusions increase in number, width and height relative to their adjacent surroundings ranging between 8 and $13 \mathrm{~nm}$ in height. These protrusions could be due to elemental titanium agglomerating on the surface. For sample S3 that was annealed at $500{ }^{\circ} \mathrm{C}$, the number of protrusions is reduced but the surface roughness has increased more than $60 \%$. Surface morphology of the sample annealed at $700{ }^{\circ} \mathrm{C}$ is quite different compared to the other samples annealed at lower temperature. The whole surface consists column-like features, an indication that the sample becomes more vertically oriented. Annealing at high temperature transforms the surface from a 2D to $3 \mathrm{D}$ columnar surface.

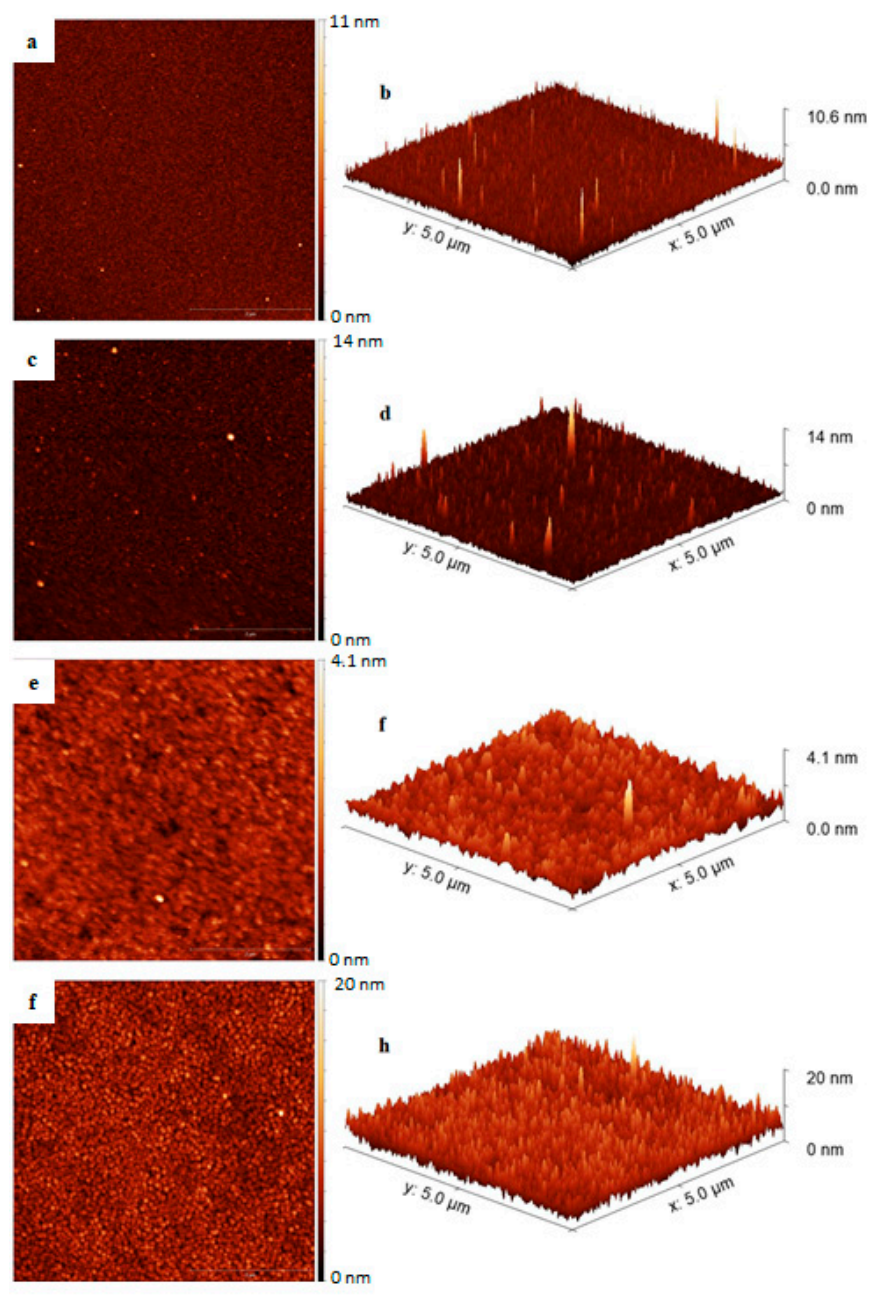

Figure 2. Atomic force microscopy (AFM) images of TiN thin films: (a,b) S1, as-grown, (c,d) S2, annealed at $300{ }^{\circ} \mathrm{C},(\mathbf{e}, \mathbf{f}) \mathrm{S} 3$, annealed at $500{ }^{\circ} \mathrm{C},(\mathbf{g}, \mathbf{h}) \mathrm{S} 4$, annealed at $700{ }^{\circ} \mathrm{C}$. 
Table 1. Root mean square (RMS) surface roughness, average grain size as measured by AFM images, optical, and electrical properties of TiN films.

\begin{tabular}{ccccccc}
\hline Sample & $\begin{array}{c}\text { Annealing } \\
\left({ }^{\circ} \mathbf{C}\right)\end{array}$ & $\begin{array}{c}\text { RMS Surface Roughness } \\
(\mathbf{n m})\end{array}$ & $\begin{array}{c}\text { Average Grain } \\
\text { Size } \mathbf{( n m )}\end{array}$ & $\begin{array}{c}\text { Band Gap } \\
(\mathbf{e V})\end{array}$ & $\begin{array}{c}\text { Carrier Concentration } \\
\left(\mathbf{c m} \mathbf{m}^{-\mathbf{3}} \mathbf{)}\right.\end{array}$ & $\begin{array}{c}\text { Resistivity } \\
\mathbf{( \Omega . c m})\end{array}$ \\
\hline S1 & As-grown & 0.505 & 11.20 & 3.67 & $9 \times 10^{18}$ & $3.0 \times 10^{-4}$ \\
S2 & 300 & 0.506 & 11.22 & 3.56 & $7 \times 10^{18}$ & $9.0 \times 10^{-4}$ \\
S3 & 500 & 0.821 & 9.245 & 3.53 & $1 \times 10^{19}$ & $20 \times 10^{-4}$ \\
S4 & 700 & 1.648 & 9.418 & 3.52 & $7 \times 10^{19}$ & $2.0 \times 10^{-4}$ \\
\hline
\end{tabular}

UV-Visible transmittance spectra were acquired for the as-grown and the annealed TiN films grown on the fused silica substrates. The optical bandgap $\left(E_{g}\right)$ of the films was determined using the following equation: $\left(\alpha_{c} E\right)^{z}=\beta_{c}\left(E-E_{g}\right)$, where $\beta_{c}$ is a constant, $\mathrm{E}$ is the photon energy, and $\mathrm{z}$ is power factor of value 2 for the direct bandgap material and $1 / 2$ for indirect bandgap. Figure 3 is a plot of $(\alpha \mathrm{E})^{2}$ as a function of photon energy (Tauc plot) of as-grown and annealed TiN films. The extrapolation of the linear portion of the curves to the horizontal axis provides the bandgap values of the films, which are listed in Table 1. Bandgap of the as-grown TiN film is $3.67 \mathrm{eV}$, which is close to the reported values $[17,31]$. The bandgap of the annealed films decreases with the increase in the annealing temperature. Bandgap of the annealed films becomes closer to the $\mathrm{TiO}_{2}$ values because at high annealing temperature the $\mathrm{Ti}-\mathrm{N}$ bond is broken and nitrogen is replaced by oxygen, forming $\mathrm{TiO}_{2}$, which was also observed in the XRD.

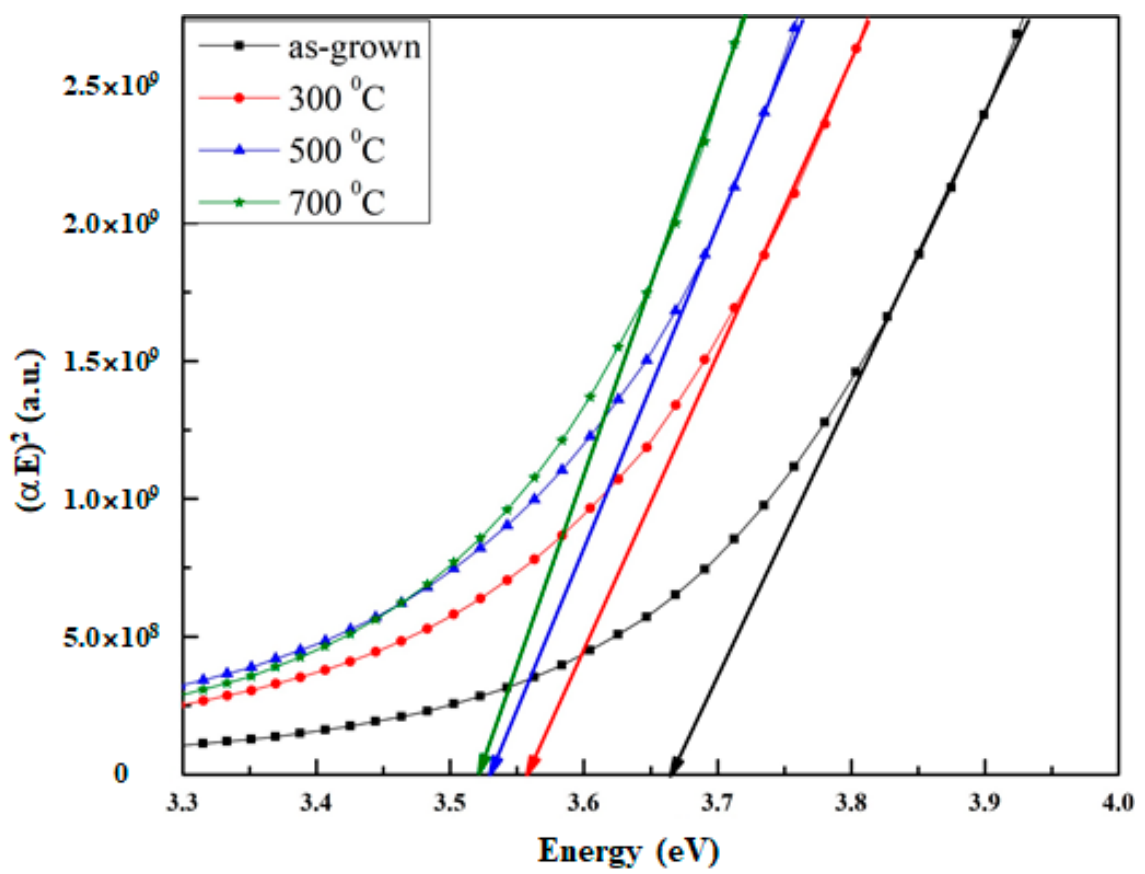

Figure 3. Tauc plots of the as-grown and the annealed TiN thin films.

Hall effect measurements revealed that all the films have n-type conductivity with high carrier concentration that increases slightly with the increase in the annealing temperature. The carrier concentration and resistivity values obtained are summarized in Table 1. High carrier concentration in titanium nitride has been attributed to the shallow donor level of the fourth valence electron of titanium not participating in the covalent bonding with nitrogen [17].

Films annealed at 300 and $500{ }^{\circ} \mathrm{C}$ have slightly higher resistivity compared to the asgrown film and the film annealed at $700{ }^{\circ} \mathrm{C}$. An increase in the resistivity can be attributed to the presence of $\mathrm{TiN}(111)$ lattice plane. This plane exhibits a rougher surface which increases charge scattering, resulting in increased resistivity [14]. This plane was found in 
the XRD patterns of the samples annealed at 300 and $500{ }^{\circ} \mathrm{C}$ but was absent in the XRD of at $700{ }^{\circ} \mathrm{C}$.

X-ray photoelectron spectroscopy (XPS) was performed to determine the chemical composition of the films and the oxidation states of different elements in the films. To study the presence of different elements throughout the thickness of the films, depth profiling was performed by etching the film's surface by low energy Ar ions for 30 s repeatedly and high-resolution spectra of Ti2p, O1s and N1s were obtained after each etching cycle.

Shown in Figure 4 is a wide-scan XPS spectrum of the as-grown TiN film. The spectrum contains Ti2p, N1s, C1s, O2p and Ar2p peaks. Presence of Ar2p peak in the spectrum is due to the use of Ar ions for etching the film during XPS acquisition. The presence of C1s peak is due to organic contamination of the sample when exposed to air after the growth. $\mathrm{C} 1 \mathrm{~s}$ binding energy of $284.8 \mathrm{eV}$ is used as a reference to correct the XPS spectra due to any charging effect.

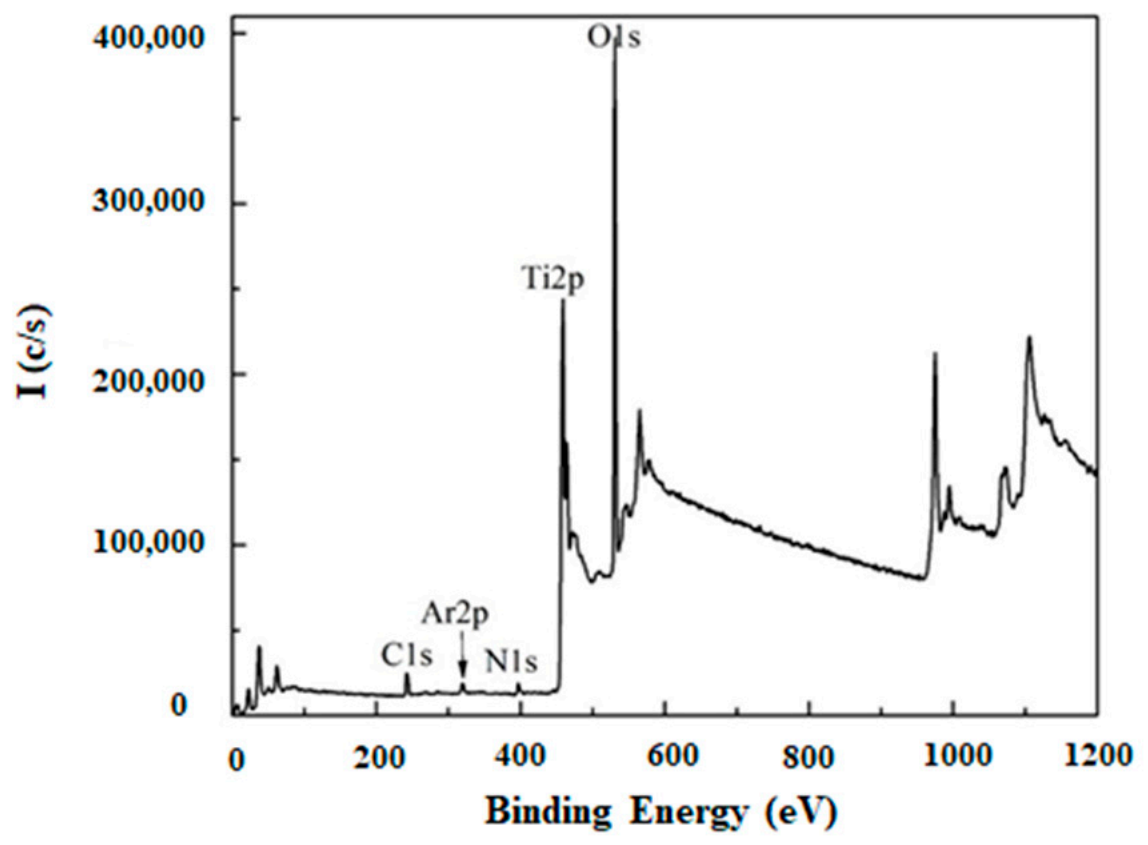

Figure 4. A wide-scan XPS spectrum of as-grown TiN film.

Shown in Figure 5a is N1s spectrum of as-grown TiN film. Peak fitting of the N1s spectrum reveals that the spectrum can be deconvoluted into two peaks, one is due to Ti-N bond and the other relatively small peak can be attributed to titanium oxynitride Ti-O-N. High-resolution XPS spectra of N1s of all the samples are shown in Figure 5b. N1s peaks corresponding to Ti-N for as-grown and samples annealed at 300 and $500{ }^{\circ} \mathrm{C}$ are centered at $396.8 \mathrm{eV}, 396.6 \mathrm{eV}$, and $397.4 \mathrm{eV}$, respectively [20,30,32]. The signal of N1s in the XPS spectrum of the sample annealed at $700{ }^{\circ} \mathrm{C}$ is too weak to determine the peak position indicating there is relatively less nitrogen in the sample. This could be due to breaking of Ti-N bond at high annealing temperature and exodus of nitrogen from the film. This is consistent with the XRD data where the intensity of TiN (200) peak is much smaller compared to the $\mathrm{TiN}(200)$ peak intensity in the other samples. The second peak of nitrogen in the N1s spectra for the as-grown and for the samples annealed at $300{ }^{\circ} \mathrm{C}$, is centered on 398.5 and $398.6 \mathrm{eV}$, which correspond to Ti-O-N formation [30,32]. Shown in Figure 5c is N1s spectra taken at different depths in the film by Ar ion etching. N1s spectra at different depths show an increase in the intensity of the peak after each etching cycle indicating more nitrogen is present in the bulk compared to the surface layers of the film. This could be due to chemisorption of oxygen from the environment resulting in oxygen occupying nitrogen position in the surface layers. 

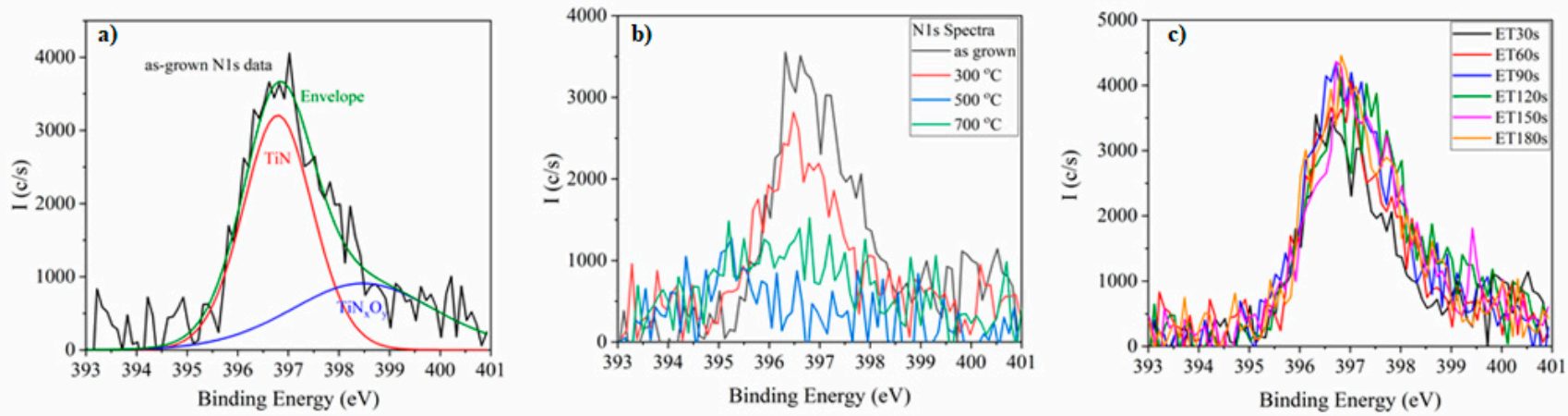

Figure 5. (a) High resolution XPS spectrum of N1s of as-grown TiN film; by peak fitting the spectrum is deconvoluted in TiN and $\mathrm{TiN}_{\mathrm{x}} \mathrm{O}_{\mathrm{y}}$ peaks. (b) High resolution XPS spectra of N1s of as-grown and annealed TiN films, taken after $30 \mathrm{~s}$ etching. (c) High resolution XPS spectra of N1s of as-grown TiN film, taken at different etching levels.

Due to spin-orbit coupling, Ti2p consists of two peaks in the XPS spectra, Ti2 $\mathrm{p}_{3 / 2}$ and Ti2 $p_{1 / 2}$. Shown in Figure $6 a$ is only the Ti2 $p_{3 / 2}$ peak for all the samples. Ti2 $p_{3 / 2}$ peaks of all the films can be deconvoluted into three different peaks, as shown in Figure $6 \mathrm{~b}$; the peak positions of the deconvoluted peaks are given in Table 2. The peak positions correspond to the binding energy of Ti- $\mathrm{O}_{2}$, Ti-O-N and Ti-N $[19,30,32,33]$. Shown in Figure $6 \mathrm{c}$ is the Ti2 $\mathrm{p}_{3 / 2}$ spectra at different depth levels in the as-grown film. In the first few surface layers, the Ti2 $\mathrm{p}_{3 / 2}$ peak consists of $\mathrm{Ti}^{-} \mathrm{O}_{2}$, Ti-O-N and Ti-N peaks, but in the bulk, the $\mathrm{Ti}^{-} \mathrm{O}_{2}$ peak disappears and instead the elemental Ti peak emerges, as shown in Figure 7. This also confirms that oxygen was chemisorbed in the film from the atmosphere after the growth. Annealing the sample at high temperature results in breaking of the Ti-N bond and formation of the Ti- $\mathrm{O}_{2}$ bond because bond formation energy of $\mathrm{Ti}^{-} \mathrm{O}_{2}$ is less than Ti-N bond formation. Enthalpy of $\mathrm{TiN}$ is $-265.8 \mathrm{KJ} / \mathrm{mol}$, whereas for $\mathrm{TiO}_{2}$ it is $-944.0 \mathrm{KJ} / \mathrm{mol}$ [34]. Therefore, near the surface where oxygen is available, the Ti- $\mathrm{O}_{2}$ bond is formed and deeper in the film where oxygen is not available after breaking of Ti-N bond, nitrogen may form $\mathrm{N}_{2}$, leaving behind elemental Ti.
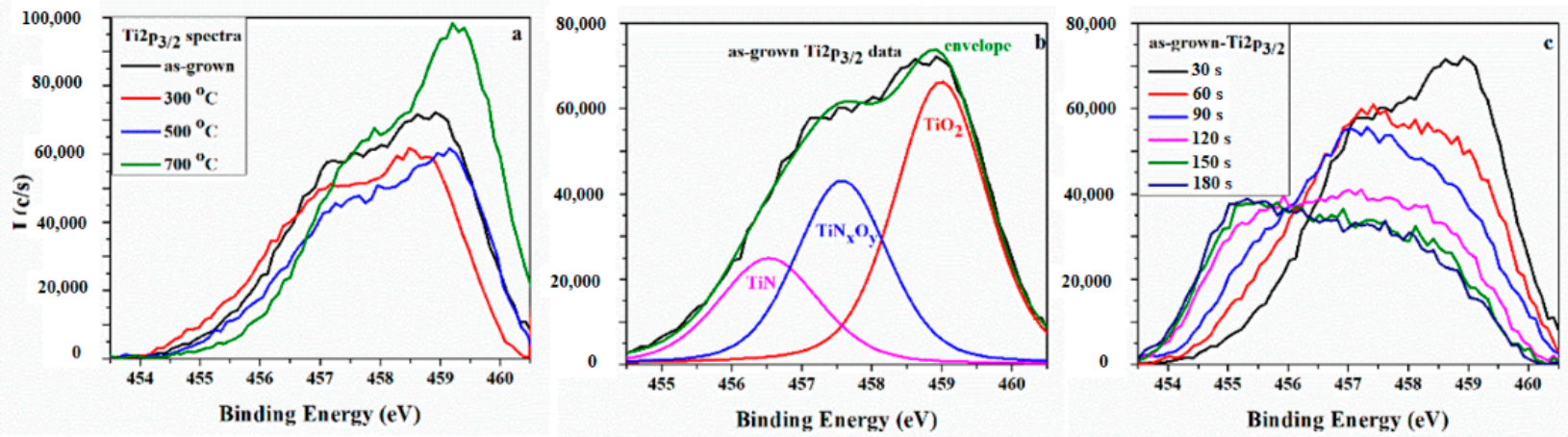

Figure 6. (a-c): (a) High resolution XPS spectra of Ti2 $\mathrm{p}_{3 / 2}$ of as-grown and annealed TiN films, taken after $30 \mathrm{~s}$ etching. (b) Peak fitting of high resolution XPS spectrum of Ti2 $\mathrm{p}_{3 / 2}$ of as-grown TiN film. (c) High resolution XPS spectra of Ti2 $\mathrm{p}_{3 / 2}$ of as-grown TiN film, taken at different etching level.

A plot of $\mathrm{N} 1 \mathrm{~s} / \mathrm{Ti} 2 \mathrm{p}_{3 / 2}$ peak atomic ratio as a function of etching time is shown in Figure $8 . \mathrm{N} 1 \mathrm{~s} / \mathrm{Ti} 2 \mathrm{p}_{3 / 2}$ peak intensity ratio increases deeper in the film for as-grown TiN film. In the case of annealed films, however, this ratio either decreases slightly or stays constant. This also confirms the fact that post-growth annealing results in breaking of the Ti-N bond, resulting in nitrogen exiting the film and leaving behind elemental titanium, which increases the chances of the film being oxidized by atmospheric oxygen. This is consistent with the $\mathrm{XRD}$ results where $\mathrm{Ti}^{-} \mathrm{O}_{2}$ phases were found in the annealed samples but not in the as-grown samples. 
Table 2. Peak positions of deconvoluted Ti2 $\mathrm{p}_{3 / 2}$.

\begin{tabular}{|c|c|c|c|c|c|}
\hline Sample & $\begin{array}{l}\text { Etching } \\
\text { Time (s) }\end{array}$ & $\mathrm{Ti}-\mathrm{O}_{2}(\mathrm{eV})$ & Ti-O-N (eV) & Ti-N (eV) & $\mathrm{Ti}(\mathrm{eV})$ \\
\hline S1 & \multirow{4}{*}{30} & 459.0 & 457.6 & 456.5 & \\
\hline S2 & & 459.0 & 458.2 & 456.8 & \\
\hline S3 & & 458.6 & 457.5 & 456.3 & \\
\hline S4 & & 459.2 & 458.5 & 457.0 & \\
\hline S1 & \multirow{4}{*}{90} & 458.6 & 457.0 & 455.6 & \\
\hline S2 & & 458.5 & 456.8 & 455.3 & \\
\hline S3 & & 458.0 & 456.5 & 455.2 & \\
\hline S4 & & 458.3 & 456.6 & 455.1 & \\
\hline S1 & \multirow{4}{*}{150} & 458.3 & 456.6 & 455.2 & \\
\hline S2 & & & 457.6 & 456.0 & 454.8 \\
\hline S3 & & & 457.3 & 455.9 & 454.6 \\
\hline S4 & & & 457.9 & 456.1 & 454.7 \\
\hline S1 & \multirow{4}{*}{210} & 458.1 & 456.3 & 454.5 & \\
\hline S2 & & & 457.6 & 455.9 & 454.7 \\
\hline S3 & & & 457.3 & 455.9 & 454.5 \\
\hline S4 & & & 457.8 & 456.0 & 454.7 \\
\hline
\end{tabular}

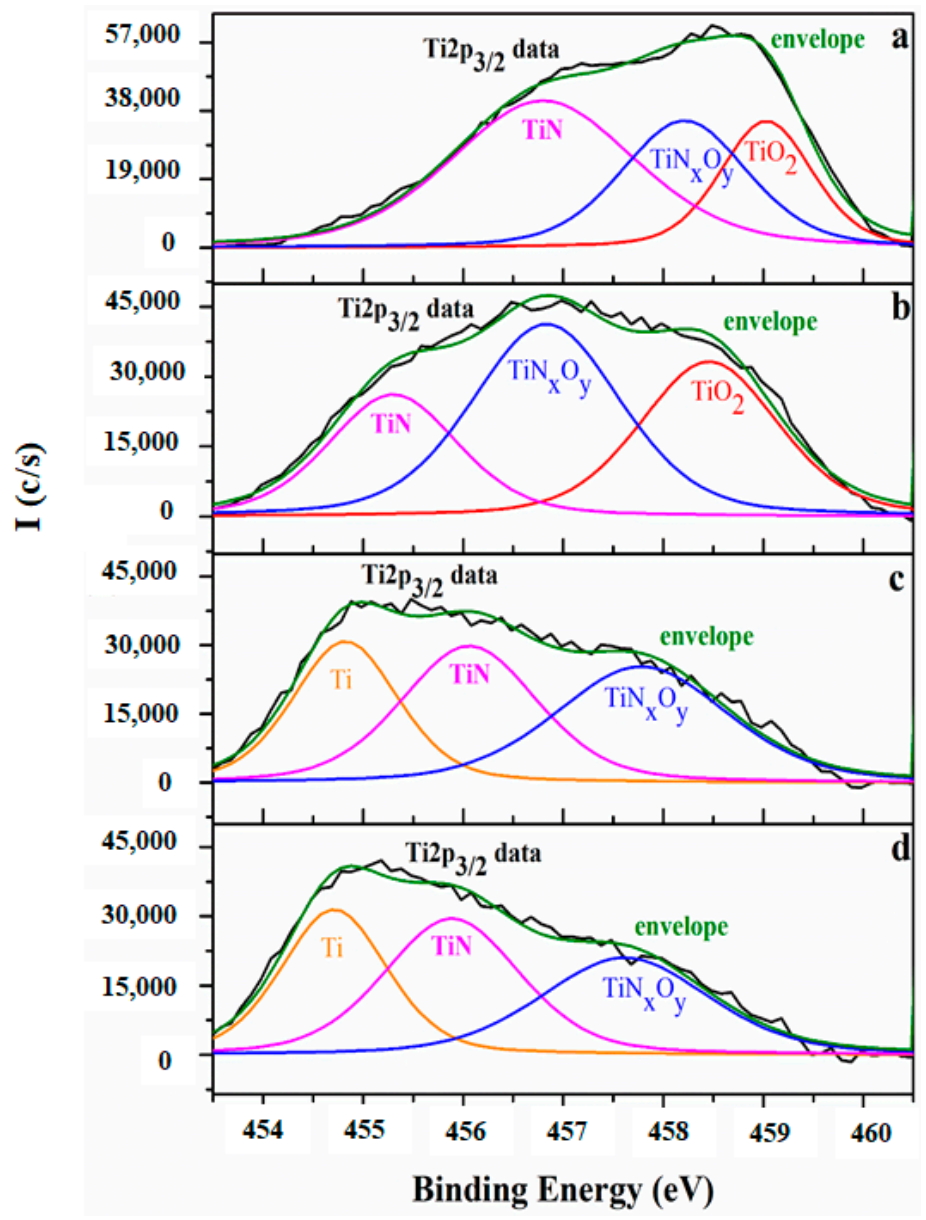

Figure 7. (a-d): Peak fitting of high resolution XPS spectrum of Ti2 $\mathrm{p}_{3 / 2}$ of S2 (annealed at $300{ }^{\circ} \mathrm{C}$ ) TiN film: (a) taken after 30 s etching; (b) taken after 90 s etching; (c) taken after 150 s etching; (d) taken after 210 s etching. 


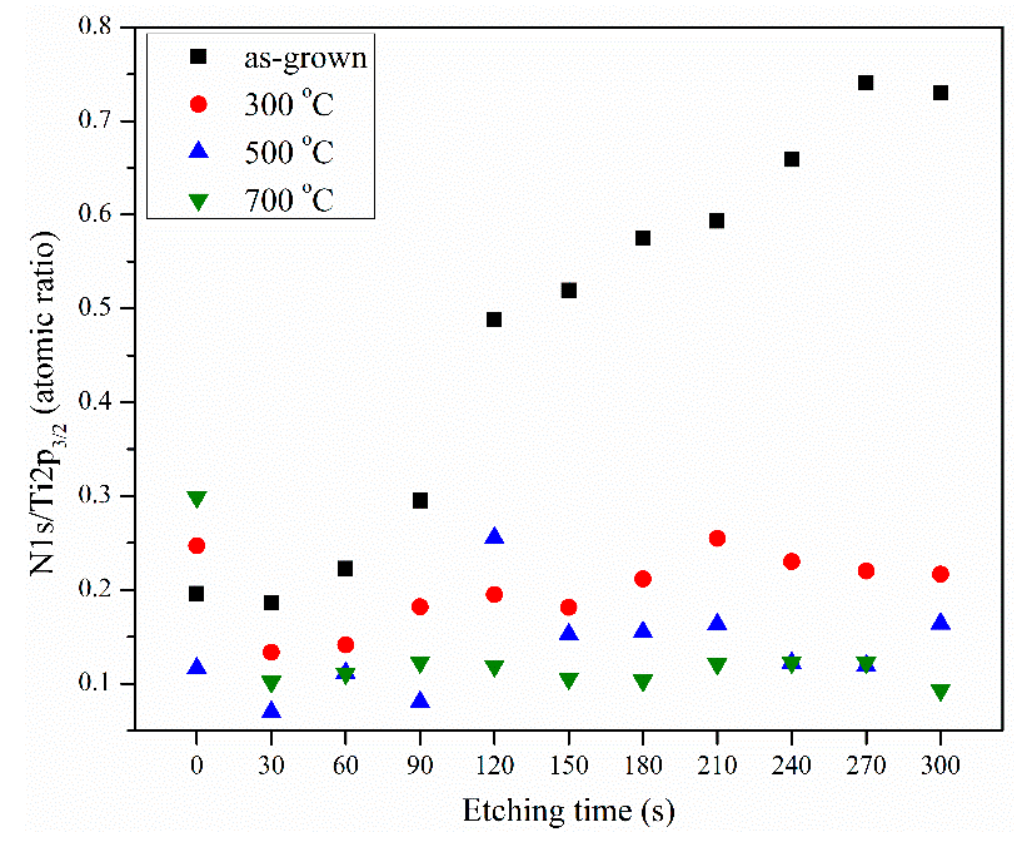

Figure 8. N1s/Ti2 $\mathrm{p}_{3 / 2}$ atomic ratio as a function of etching time of as-grown and annealed TiN films.

\section{Conclusions}

Titanium nitride thin films were prepared by RF magnetron sputtering of Ti target in $\mathrm{N}_{2}$ and Ar mixture of gases at room temperature followed by the post-growth annealing at different temperatures in nitrogen ambient. Structural and electrical properties were extremely dependent on the post growth annealing treatment. Annealing seemed to enhance the crystallinity of the films. Surface roughness increased, and the average grain size decreased with the increase in the annealing temperatures. Optical bandgap of the as-grown TiN thin film was $3.67 \mathrm{eV}$ and it decrease consistently with the increase in the post growth annealing temperature. We found that post-growth annealing in nitrogen ambient, although enhancing the crystallinity of the TiN films, also results in an increase of $\mathrm{TiO}_{2}$ phases. All of the films exhibited n-type conductivity and the carrier concentration increased with the increase in the annealing temperature. XPS study of the films confirms the formation of $\mathrm{Ti}-\mathrm{N}$ bonds along with $\mathrm{TiO}_{2}$ formation due to chemisorbed oxygen in the surface layers. Depth profiling of the film revealed that intensity of N1s peak increased whereas O1s peak decreased with each etching level. As-grown film has stoichiometric TiN, whereas annealed films had less than stoichiometric nitrogen in the film, indicating breaking of Ti-N bond at high annealing temperatures.

Author Contributions: M.B.H. conceived the project and the manuscript. M.M., M.B.H., Q.A.D. and M.B.M. contributed to the evaluation and interpretation of the published data. All authors have read and agreed to the published version of the manuscript.

Funding: We would like to acknowledge the Deanship of Scientific Research at King Fahd University of Petroleum and Minerals for the financial support for this work through internal research grant \# IN131056.

Data Availability Statement: Data sharing is not applicable to this article.

Conflicts of Interest: The authors declare no conflict of interest.

\section{References}

1. Lemme, M.C.; Efavi, J.; Mollenhauer, T.; Schmidt, M.; Gottlob, H.; Wahlbrink, T.; Kurz, H. Nanoscale TiN metal gate technology for CMOS integration. Microelectron. Eng. 2006, 83, 1551-1554. [CrossRef]

2. Fillot, F.; Morel, T.; Minoret, S.; Matko, I.; Maîtrejean, S.; Guillaumot, B.; Chenevier, B.; Billon, T. Investigations of titanium nitride as metal gate material, elaborated by metal organic atomic layer deposition using TDMAT and NH3. Microelectron. Eng. 2005, 82, 248-253. [CrossRef] 
3. Achour, A.; Chaker, M.; Achour, H.; Arman, A.; Islam, M.; Mardani, M.; Boujtita, M.; Le Brizoual, L.; Djouadi, M.; Brousse, T. Role of nitrogen doping at the surface of titanium nitride thin films towards capacitive charge storage enhancement. J. Power Sources 2017, 359, 349-354. [CrossRef]

4. Lukosius, M.; Walczyk, C.; Fraschke, M.; Wolansky, D.; Richter, H.; Wenger, C. High performance metal-insulator-metal capacitors with atomic vapor deposited HfO2 dielectrics. Thin Solid Films 2010, 518, 4380-4384. [CrossRef]

5. Sundgren, J.-E. Structure and properties of TiN coatings. Thin Solid Films 1985, 128, 21-44. [CrossRef]

6. Sedira, S.; Achour, S.; Avci, A.; Eskizeybek, V. Physical deposition of carbon doped titanium nitride film by DC magnetron sputtering for metallic implant coating use. Appl. Surf. Sci. 2014, 295, 81-85. [CrossRef]

7. Sabitzer, C.; Steinkellner, C.; Koller, C.; Polcik, P.; Rachbauer, R.; Mayrhofer, P. Diffusion behavior of C, Cr, and Fe in arc evaporated TiN- and CrN-based coatings and their influence on thermal stability and hardness. Surf. Coat. Technol. 2015, 275, 185-192. [CrossRef]

8. Chung, K.; Liu, G.; Duh, J.; Wang, J. Biocompatibility of a titanium-aluminum nitride film coating on a dental alloy. Surf. Coat. Technol. 2004, 188-189, 745-749. [CrossRef]

9. Franks, W.; Schenker, I.; Schmutz, P.; Hierlemann, A. Impedance Characterization and Modeling of Electrodes for Biomedical Applications. IEEE Trans. Biomed. Eng. 2005, 52, 1295-1302. [CrossRef] [PubMed]

10. Jeyachandran, Y.; Narayandass, S.; Mangalaraj, D.; Areva, S.; Mielczarski, J. Properties of titanium nitride films prepared by direct current magnetron sputtering. Mater. Sci. Eng. A 2007, 445, 223-236. [CrossRef]

11. Yu, S.; Frapper, G.; Zhang, L.; Zeng, Q.; Oganov, A.R. Phase stability, chemical bonding and mechanical properties of titanium nitrides: A first-principles study. Phys. Chem. Chem. Phys. 2015, 17, 11763-11769. [CrossRef]

12. Zhao, G.; Zhang, T.; Zhang, T.; Wang, J.; Han, G. Electrical and optical properties of titanium nitride coatings prepared by atmospheric pressure chemical vapor deposition. J. Non-Cryst. Solids 2008, 354, 1272-1275. [CrossRef]

13. Cheng, H.-E.; Wen, Y.-W. Correlation between process parameters, microstructure and hardness of titanium nitride films by chemical vapor deposition. Surf. Coat. Technol. 2004, 179, 103-109. [CrossRef]

14. Guo, H.; Chen, W.; Shan, Y.; Wang, W.; Zhang, Z.; Jia, J. Microstructures and properties of titanium nitride films prepared by pulsed laser deposition at different substrate temperatures. Appl. Surf. Sci. 2015, 357, 473-478. [CrossRef]

15. Xiang, W.; Liu, Y.; Zhang, J. Influence of Microstructure on the Electrical Properties of Heteroepitaxial TiN Films. Electron. Mater. Lett. 2018, 14, 314-318. [CrossRef]

16. Mucha, N.R.; Som, J.; Shaji, S.; Fialkova, S.; Apte, P.R.; Balasubramanian, B.; Shield, J.E.; Anderson, M.; Kumar, D. Electrical and optical properties of titanium oxynitride thin films. J. Mater. Sci. 2020, 55, 5123-5134. [CrossRef]

17. Solovan, M.N.; Brus, V.V.; Maistruk, E.V.; Maryanchuk, P.D. Electrical and optical properties of TiN thin films. Inorg. Mater. 2013, 50, 40-45. [CrossRef]

18. Kavitha, A.; Kannan, R.; Reddy, P.S.; Rajashabala, S. The effect of annealing on the structural, optical and electrical properties of Titanium Nitride (TiN) thin films prepared by DC magnetron sputtering with supported discharge. J. Mater. Sci. Mater. Electron. 2016, 27, 10427-10434. [CrossRef]

19. Zhang, J.; Chen, T.P.; Li, X.D.; Liu, Y.C.; Liu, Y.; Yang, H.Y. Investigation of localized surface plasmon resonance of TiN nanoparticles in TiN_xO_y thin films. Opt. Mater. Express 2016, 6, 2422-2433. [CrossRef]

20. Ponon, N.K.; Appleby, D.J.; Arac, E.; King, P.; Ganti, S.; Kwa, K.S.; O’Neill, A. Effect of deposition conditions and post deposition anneal on reactively sputtered titanium nitride thin films. Thin Solid Films 2015, 578, 31-37. [CrossRef]

21. Wang, Z.; Wang, X.; Liu, W.; Ji, X.; Wang, C. Ohmic contact formation mechanisms of TiN film on 4H-SiC. Ceram. Int. 2020, 46, 7142-7148. [CrossRef]

22. Krockenberger, Y.; Karimoto, S.-I.; Yamamoto, H.; Semba, K. Coherent growth of superconducting TiN thin films by plasma enhanced molecular beam epitaxy. J. Appl. Phys. 2012, 112, 083920. [CrossRef]

23. Maurya, K.C.; Shalaev, V.M.; Boltasseva, A.; Saha, B. Reduced optical losses in refractory plasmonic titanium nitride thin films deposited with molecular beam epitaxy. Opt. Mater. Express 2020, 10, 2679-2692. [CrossRef]

24. Yokota, K.; Nakamura, K.; Kasuya, T.; Ohnishi, M. Phase composition and crystalline structure of titanium nitride deposited on silicon by an ion-beam assisted deposition technique. Nucl. Instrum. Methods Phys. Res. Sect. B Beam Interact. Mater. Atoms 2003, 206, 386-389. [CrossRef]

25. Zhu, Y.F.; Li, F.S.; Rong, H.; Tong, L.; Zhao, Y.F.; Yang, S.; Jian, Z.; An, D.S.; Yun, G. Remote plasma-enhanced atomic layer deposition of metallic TiN films with low work function and high uniformity. J. Vac. Sci. Technol. A 2018, 36, 041501. [CrossRef]

26. Andrievski, R.A.; Dashevsky, Z.M.; Kalinnikov, G.V. Conductivity and the Hall coefficient of nanostructured titanium nitride films. Tech. Phys. Lett. 2004, 30, 930-932. [CrossRef]

27. Nečas, D.; Klapetek, P. Gwyddion: An open-source software for SPM data analysis. Open Phys. 2012, 10, 181-188. [CrossRef]

28. Haider, M.B. XPS Depth Profile Analysis of Zn3N2 Thin Films Grown at Different N2/Ar Gas Flow Rates by RF Magnetron Sputtering. Nanoscale Res. Lett. 2017, 12, 5. [CrossRef] [PubMed]

29. van der Pauw, L.J. A method of measuring specific resistivity and Hall effect of discs of arbitrary shape. Philips Res. Rep. 1958, 13, 1-9.

30. Solís-Pomar, F.; Nápoles, O.; Robaina, O.V.; Gutierrez-Lazos, C.; Fundora, A.; Colin, A.; Pérez-Tijerina, E.; Melendrez, M. Preparation and characterization of nanostructured titanium nitride thin films at room temperature. Ceram. Int. 2016, 42, 7571-7575. [CrossRef] 
31. Ghobadi, N.; Ganji, M.; Luna, C.; Arman, A.; Ahmadpourian, A. Effects of substrate temperature on the properties of sputtered TiN thin films. J. Mater. Sci. Mater. Electron. 2015, 27, 2800-2808. [CrossRef]

32. Subramanian, B.; Ananthakumar, R.; Jayachandran, M. Structural and tribological properties of DC reactive magnetron sputtered titanium/titanium nitride (Ti/TiN) multilayered coatings. Surf. Coat. Technol. 2011, 205, 3485-3492. [CrossRef]

33. Liang, H.; Xu, J.; Zhou, D.; Sun, X.; Chu, S.; Bai, Y. Thickness dependent microstructural and electrical properties of TiN thin films prepared by DC reactive magnetron sputtering. Ceram. Int. 2016, 42, 2642-2647. [CrossRef]

34. Dean, J.A. Lang's Handbook of Chemistry; McGraw Hill: New York, NY, USA, 1999; Volume 42, p. 120. 